\title{
Renewable Energy and Oceanic Structures: Part IV
}

1 José A.F.O. Correia PhD, MSc, CEng

Researcher, Department of Civil Engineering, Faculty of Engineering, University of Porto, Rua Dr. Roberto Frias, s/n, 4200-465 Porto, Portugal

2 Tiago Fazeres-Ferradosa PhD, MSc, CEng

Researcher, Faculty of Engineering of the University of Porto, Department of Civil Engineering, Hydraulics, Water Resources and Environmental Division, CIIMAR - Interdisciplinary Centre of Marine and Environmental Research, Marine Energy Research Group, Porto, Portugal, Rua Dr. Roberto Frias, s/n, 4200-465 Porto, Portugal
3 Shun-Peng Zhu PhD, MSc, MEng

Professor, School of Mechanical and Electrical Engineering, University of Electronic Science and Technology of China, Chengdu, China

4 Abílio M.P. De Jesus PhD, MSc, MEng

Associate Professor, Department of Mechanical Engineering, Faculty of Engineering, University of Porto, Rua. Dr. Roberto Frias, s/n, 4200-465 Porto, Portugal
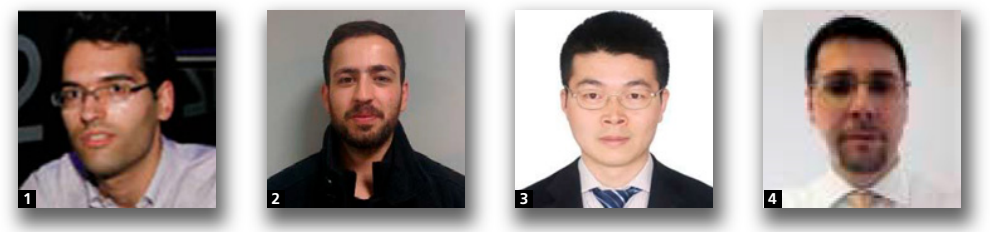

Maritime Engineering covers the investigation on safe and sustainable engineering in salt-water environment and publishes scientific and technical works regarding the management, planning, design, analysis, construction, operation, maintenance and applied research related to renewable energy and oceanic engineering. Works from industry and academia are published in this journal conveying advanced research on developing, designing or constructing schemes, as well as good practices in the field.

This issue on Renewable Energy and Oceanic Structures (Correia et al., 2019a) corresponds to the fourth part of the selected papers from the thematic session (Alessi et al., 2019) with the same name that took place at the Faculty of Engineering of the University of Porto, on 5-7 September 2018. The first part related to this thematic (Correia et al., 2019a) included the following aspects (Rege and Pavlou, 2019; Pavlou and Correia, 2019; Jiang et al., 2019): structural integrity of offshore structures; dynamic response of pipelines under flexural loads; and finally, the assessment of wave energy resources. The second part (Correia et al., 2019b) covered the topics related to the floods \& floodworks, hydraulics \& hydrodynamics, dredging \& reclamation, foundations, fatigue, maintenance \& inspection, risk \& probability analysis (Tanim et al., 2019; Dang et al., 2019; Fazeres-Ferradosa et al., 2019). The third part (Correia et al., 2020) was focused in the following topics: maritime engineering; offshore engineering; mathematical modelling; failure analysis; and, risk \& probabilistic analysis. Meng et al. (2020a) presented an investigation on the collaborative design of maritime/offshore structures based on reliability analysis and sequential optimisation. On the other hand, the scientific work developed by Wang et al. (2020) focused in an advanced investigation based on multi-population genetic algorithm to improve the computational efficiency of dynamic probabilistic assessment of complex structures.

This fourth thematic issue on Renewable Energy and Oceanic Structures of the Proceedings of the ICE in Maritime Engineering focuses on the following topics: maritime engineering, offshore engineering, mathematical modelling, fatigue and risk \& probabilistic analysis.

The first paper (Meng et al., 2020b) proposed a reliabilitybased design and optimisation (RBDO) with a mean-value second-order saddle point approximation strategy applied to design problem of a wellhead platform. RBDO approach combined with a saddle point approximation proved to be a powerful method to enhance the reliability of offshore structures. An engineering case study was selected to illustrate the proposed method.

In the second paper (Mourão et al., 2020), the authors proposed a global-local fatigue methodology applied to an offshore jacket-type platform of welded tubular joints using a local approach based on a notch strain damage parameter. In this research work, the local stress/strain histories were computed through the Neuber's rule combined with the Ramberg-Osgood description using cyclic elastoplastic behaviour for the structural steel under consideration. 
The maximum stress concentration factor was used. Fatigue damage accumulation was calculated using the PalmgrenMiner linear damage rule and the design strain-life curve proposed by the Coffin-Manson relation.

Guest and associate editors of the Maritime Engineering journal are very grateful to the authors and reviewers that contributed to this issue. A special thanks to the ICE Publishing staff for the opportunity to collaborate with the journal.

\section{REFERENCES}

Alessi L, Correia JAFO and Fantuzzi N (2019) Initial design phase and tender designs of a jacket structure converted into a retrofitted offshore wind turbine. Energies 12(4): 659. https://doi.org/10.3390/ en12040659.

Correia JAFO, Fazeres-Ferradosa T, Castro JM, Fantuzzi N and De Jesus AMP (2019a) Editorial: Renewable Energy and Oceanic Structures: Part I. Proceedings of the Institution of Civil Engineers - Maritime Engineering 172(1): 12. https://doi.org/10.1680/jmaen.2019.172.1.1.

Correia JAFO, Ferradosa T, Castro JM, Pavlou DG and De Jesus AMP (2019b) Editorial: Renewable Energy and Oceanic Structures: Part II. Proceedings of the Institution of Civil Engineers Maritime Engineering 172(3): 71-72, https://doi.org/10.1680/ jmaen.2019.172.3.71.

Correia JAFO, Mendes P, Fazeres-Ferradosa T and Zhu S (2020) Renewable Energy and Oceanic Structures: Part III. Proceedings of the Institution of Civil Engineers - Maritime Engineering 173(1): pp. 1-2, https://doi.org/10.1680/jmaen.2020.173.1.1.

Dang TV, Morato PG, Mai QA and Rigo P (2019) Optimal inspection and repair scheduling for mitre lock gates. Proceedings of the Institution of Civil Engineers - Maritime Engineering 172(3): 95-103, https://doi.org/10.1680/jmaen.2019.10.
Fazeres-Ferradosa T, Taveira-Pinto F, Rosa-Santos P and Chambel J (2019) A review of reliability analysis of offshore scour protections. Proceedings of the Institution of Civil Engineers - Maritime Engineering 172(3): 104-117, https://doi.org/10.1680/ jmaen.2019.11.

Jiang B, Wu G, Ding J et al. (2019) Assessment of the wave energy resource in the South China Sea. Proceedings of the Institution of Civil Engineers - Maritime Engineering 172(1): pp. 23-33, https://doi.org/10.1680/jmaen.2018.29.

Meng D, Li Y, Zhu SP et al. (2020a) Collaborative maritime design using sequential optimisation and reliability assessment. Proceedings of the Institution of Civil Engineers Maritime Engineering 173(1): 3-12, https://doi.org/10.1680/ jmaen.2019.27.

Meng D, Hu Z, Wu P et al. (2020b) Reliability-based optimisation for offshore structures using saddlepoint approximation. Proceedings of the Institution of Civil Engineers - Maritime Engineering 173(2): 33-42, https://doi.org/10.1680/jmaen.2020.2.

Mourão A, Correia JAFO, Ávila BV, et al. (2020) A fatigue damage evaluation using local damage parameters for an offshore structure. Proceedings of the Institution of Civil Engineers Maritime Engineering 173(2): 43-57, https://doi.org/10.1680/ jmaen.2019.24.

Pavlou DG and Correia JAFO (2019) Dynamic response of pipelines under impact and harmonic loading. Proceedings of the Institution of Civil Engineers - Maritime Engineering 172(1): 15-22, https://doi.org/10.1680/jmaen.2019.2.

Rege K and Pavlou DG (2019) Effect of stop holes on structural integrity of offshore structures: A numerical model. Proceedings of the Institution of Civil Engineers - Maritime Engineering 172(1): pp. 3-14, https://doi.org/10.1680/jmaen.2018.34.

Tanim AH and Akter A (2019) Storm-surge modelling for cyclone Mora in the northern Bay of Bengal. Proceedings of the Institution of Civil Engineers - Maritime Engineering 172(3): pp. 73-94. 